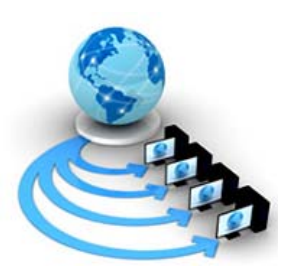

Volume 8, No. 9, November-December 2017

International Journal of Advanced Research in Computer Science

RESEARCH PAPER

Available Online at www.ijarcs.info

\title{
A NEARBY PLACE THROUGH A GRAPHICAL REPRESENTATION
}

\author{
T.Vyshnavi, S.N.S.M.Praneetha, M.Jahnavi \\ III/IV B.Tech, Department of IT, PVPSIT \\ Vijayawada, India
}

\author{
Dr. J. Rajendra Prasad \\ Professor, Department of IT, PVPSIT \\ Vijayawada, India
}

\begin{abstract}
Hotels and restaurants are the places where they can provide food, accommodation and services to the guests who are willing to pay for what they offer and experienced by them. Basically when people are willing to hangout, they first prefer good service, satisfaction, and good products. So, because of these preferences people are introduced to taverns (hotels and restaurants). Generally, people choose hotels and restaurants according to their budgets, because every person cannot stay in 5 star hotel and everybody cannot eat in 5 star hotel. So, people choose according to their capacity. So, our application is here to make ease for the people to choose and find out hotels in one of the city in South India which is nothing but Vijayawada. So, people can find out the hotels and food plazas in Vijayawada according to their capacity. The whole information of taverns and food plaza's is provided by our application with also their website link.
\end{abstract}

Keywords: Event Management, Data Visualization.

\section{INTRODUCTION}

An establishment that provides for services such as accommodations, meals, and other services for travelers and tourists. Accommodation can be for any purpose such as overnight stay, holidays, business stay, transit etc. In Restaurants, you can try quality dishes cooked by the professional chefs. Fresh seasonal products are available on every menu. A Restaurant is an establishment which prepares and serves food and drink to customers in return for money, either paid before the meal, after the meal, or with a running tab. Meals are generally served and eaten on premises, but many restaurants also offer take out and food delivery services. Restaurants vary greatly in appearance and offerings, including a wide variety of the main chef's cuisines and service models Sometimes its just one thing SHOPPING FOR FOOD. People will chose hotels and restaurants by rating.

\section{DATA COLLECTION}

This application is meant for showing a particular hotel or restaurant spot at a particular location in a particular city based on Geographical representation. This data application help's one to get perfect idea about hotels and restaurants, cost etc. In detail about the cost, contact number, website, rating for that particular tavern. It is easy to identify the spot by using a route map which was linked in the application. The main goal of this application is to get full fledged data about a particular place that is chosen by a person. Some of the attributes have been presented in this application they are:

\begin{tabular}{|c|c|c|l|}
\hline S. NO & $\begin{array}{c}\text { NAME OF } \\
\text { THE } \\
\text { HOTEL }\end{array}$ & LATITUDE & $\begin{array}{l}\text { LONGIT- } \\
\text { UDE }\end{array}$ \\
\hline $\begin{array}{c}\text { RESTAURANT } \\
\text { OR HOTEL }\end{array}$ & $\begin{array}{c}\text { VEG OR } \\
\text { NON-VEG }\end{array}$ & $\begin{array}{c}\text { NO. OF } \\
\text { ROOMS }\end{array}$ & $\begin{array}{l}\text { WEBSITE } \\
\text { ADDRESS }\end{array}$ \\
\hline $\begin{array}{c}\text { CONTACT } \\
\text { NUMBER }\end{array}$ & $\begin{array}{c}\text { COST OF } \\
\text { ROOM } \\
\text { PER DAY }\end{array}$ & $\begin{array}{c}\text { A.C OR } \\
\text { NON A.C }\end{array}$ & $\begin{array}{c}\text { NO. OF } \\
\text { A.C } \\
\text { ROOMS }\end{array}$ \\
\hline
\end{tabular}

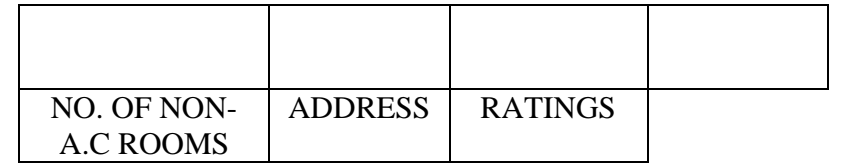

\section{TECHNOLOGIES USED}

\section{A. MICROSOFT EXCEL}

Microsoft excel is a spread sheet developed by Microsoft for Windows, macOS, Android and iOS. It features calculation, graphing tools, pivot tables, and a macro programming language called Visual Basic for Applications. It has been a very widely applied spreadsheet for these platforms, especially since version 5 in 1993. The Windows version of Excel supports programming through Microsoft's Visual Basic for Applications (VBA), which is a dialect of Visual Basic. Programming with VBA allows spreadsheet manipulation that is awkward or impossible with standard spreadsheet techniques. Programmers may write code directly using the Visual Basic Editor (VBE), which includes a window for writing code, debugging code, and code module organization environment. The user can also implement numerical methods in Microsoft excel [1],[6]. 

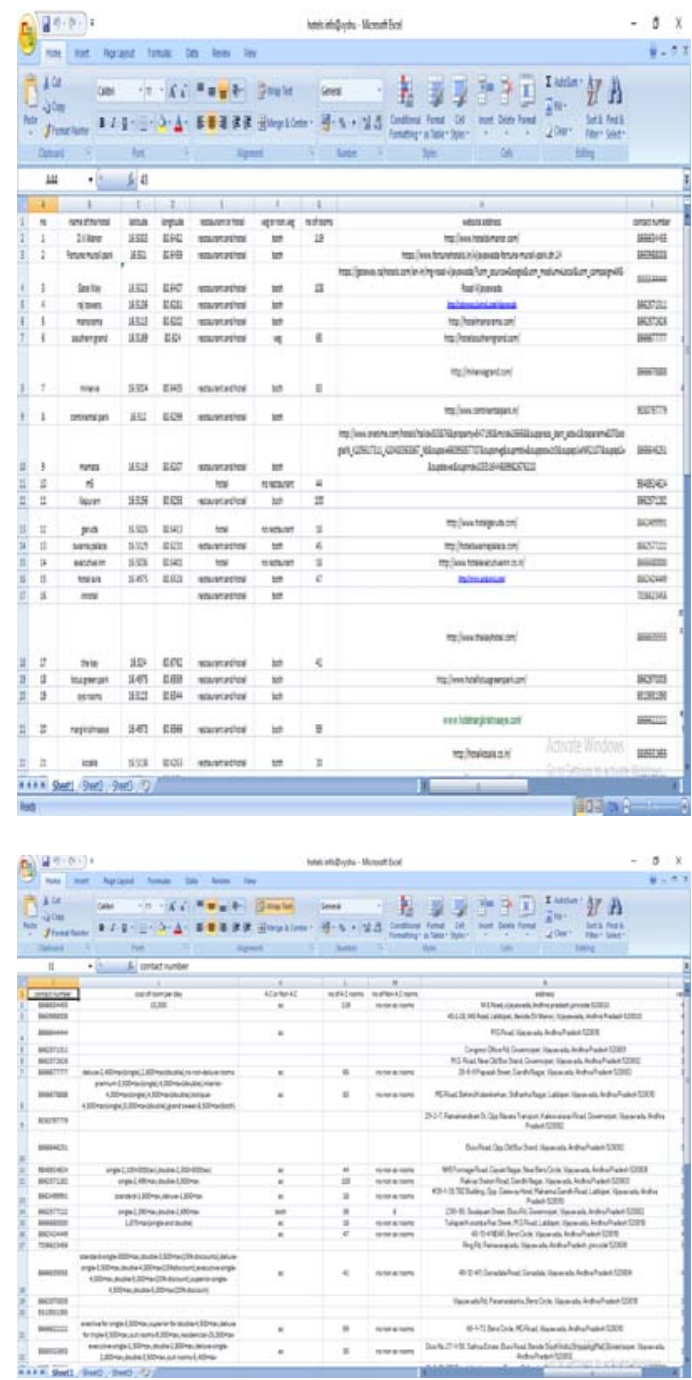

\section{B. MICROSOFT TABLUEA}

Tableau is a data visualization tool which is viewed by many disciplines as a modern equivalent of visual communication. Tableau also has a mapping functionality, and is able to plot latitude and longitude co-ordinates. It involves the creation and study of the visual representation of data, meaning "information that has been abstracted in some schematic form, including attributes or variables for the units of information". The primary goal of data visualization is to communicate information clearly and efficiently via statistical graphics, plots and information graphics [2],[5],[6].

\section{FILE}

The new option will be used for creating a tableau file and load all the necessary attributes into it. The tableau file will be saved with an extension: .tbsl .These files can be various types of format of data.

\section{DASHBOARD}

A dashboard is a collection of several worksheets and supporting information shown in a single place so you can compare and monitor a variety of data simultaneously. For example, you may have a set of views that you review every day. Rather than flipping through each worksheet, you can create a dashboard that displays all the views at once [5],[6].

\section{E. SERVER}

Tableau Server public is the option where the tableau application is linked with the web application to get the information. The Tableau Software is an online solution for sharing, distributing, and collaborating on content created in Tableau. Shareable. Create workbooks and views, dashboards, and data sources in Tableau Desktop, and then publish this content to the server [2],[5],[6].

\section{F. MAPS}

The application needs to visualize the data geographically; we can plot the data on a map in Tableau [3], [4].

\section{G. DATA PREPROCESSING}

Latitude and Longitude are known in every location on earth's surface. Latitude is a measurement on a map of location north (or) south Longitude is a measurement on a map of location east (or) west. By taking this Latitude and Longitude it is used to spot a particular location at the spot by this application which is presented.

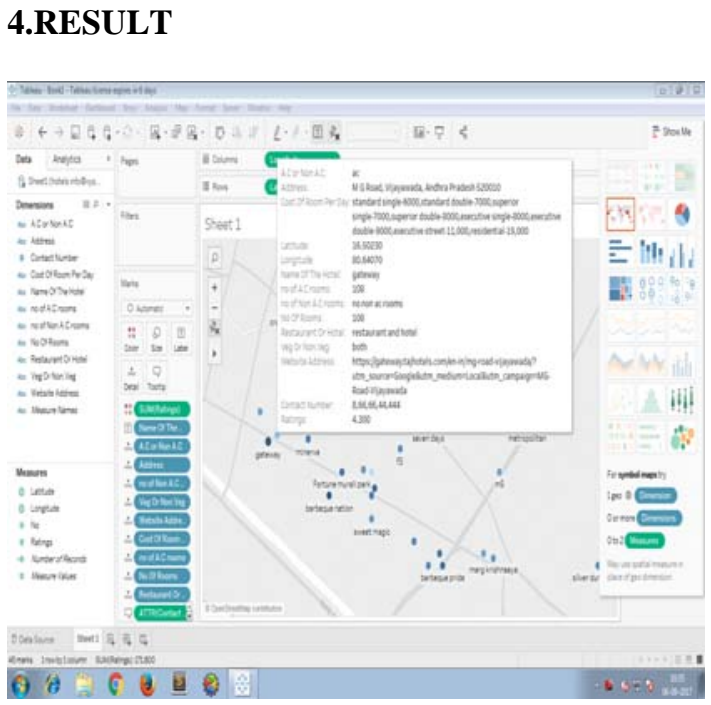

Fig: 1.1 Shows the information about one tavern

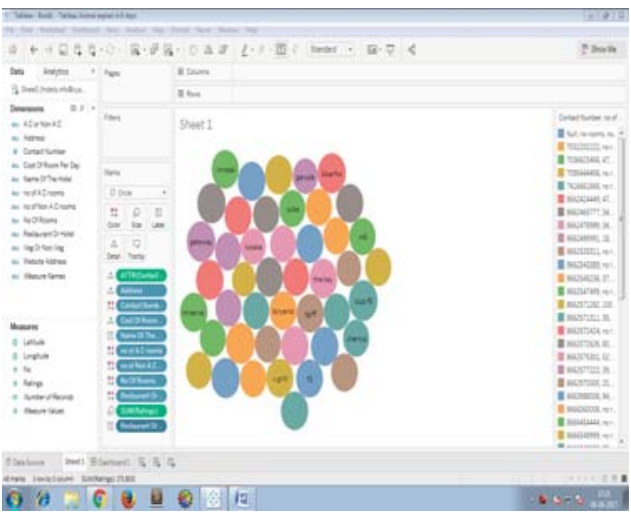

Fig: 1.2 Shows the information about all taverns by bubble representation. 


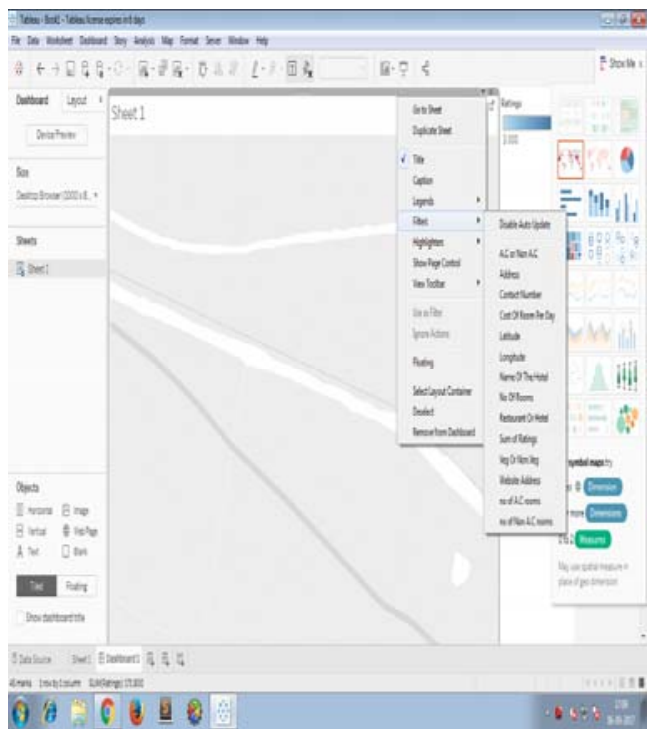

Fig: 2.1 Shows the icon of small arrow which represents filters.

\section{CONCLUSION}

Hotels and Restaurants are changing according to the present society. Now a days people see everything in websites or applications.By above application people will easily recognise the hotels and restaurants in vijayawada city.

\section{REFERENCES}

[1] https://www.tutorialspoint.com/excel/

[2] https://community.tableau.com/community/viz-talk/tableaucommunity-library/twl

[3] https://www.timeanddate.com/geography/longitudelatitude.html

[4] https://www.latlong.net/

[5] Pat Hanrahan, Christian Chabot, Chris Stolte. "Tableau Software"

[6] Ch. Likhitha, Geographical Representation of Engineering Colleges Using Data Visualization Tool, International Journal of Modern Sciences and Engineering Technology (IJMSET) ISSN 2349-3755; Available at https://www.ijmset.com Volume 4, Issue 5, 2017, pp.1-5 